Cite this: Phys. Chem. Chem. Phys., 2012, 14, 7392-7399

\title{
Microstructural impact of anodic coatings on the electrochemical chlorine evolution reaction $\dagger$
}

\author{
Ruiyong Chen, $f^{a}$ Vinh Trieu, ${ }^{a}$ Aleksandar R. Zeradjanin, ${ }^{b}$ Harald Natter, ${ }^{a}$ \\ Detre Teschner, ${ }^{c}$ Jürgen Kintrup, ${ }^{d}$ Andreas Bulan, ${ }^{d}$ Wolfgang Schuhmann ${ }^{b}$ and \\ Rolf Hempelmann*a
}

Received 4th January 2012, Accepted 12th April 2012

DOI: $10.1039 / \mathbf{c} 2 \mathrm{cp41163f}$

Sol-gel $\mathrm{Ru}_{0.3} \mathrm{Sn}_{0.7} \mathrm{O}_{2}$ electrode coatings with crack-free and mud-crack surface morphology deposited onto a Ti-substrate are prepared for a comparative investigation of the microstructural effect on the electrochemical activity for $\mathrm{Cl}_{2}$ production and the $\mathrm{Cl}_{2}$ bubble evolution behaviour. For comparison, a state-of-the-art mud-crack commercial $\mathrm{Ru}_{0.3} \mathrm{Ti}_{0.7} \mathrm{O}_{2}$ coating is used. The compact coating is potentially durable over a long term compared to the mud-crack coating due to the reduced penetration of the electrolyte. Ti L-edge X-ray absorption spectroscopy confirms that a $\mathrm{TiO}_{x}$ interlayer is formed between the mud-crack $\mathrm{Ru}_{0.3} \mathrm{Sn}_{0.7} \mathrm{O}_{2}$ coating and the underlying Ti-substrate due to the attack of the electrolyte. Meanwhile, the compact coating shows enhanced activity in comparison to the commercial coating, benefiting from the nanoparticle-nanoporosity architecture. The dependence of the overall electrode polarization behaviour on the local activity and the bubble evolution behaviour for the $\mathrm{Ru}_{0.3} \mathrm{Sn}_{0.7} \mathrm{O}_{2}$ coatings with different surface microstructure are evaluated by means of scanning electrochemical microscopy and microscopic bubble imaging.

\section{Introduction}

Chlorine is one of the important building blocks for the whole chemical and pharmaceutical industry. The continuous expansion of the demand for $\mathrm{Cl}_{2}$ supply reached about 65 million tonnes in 2010 worldwide. ${ }^{1}$ In the energy-intensive chlor-alkali process, the most efficient membrane process consumes around $2500 \mathrm{~kW}$ h per ton $\mathrm{Cl}_{2}$, accounting for $50 \%$ of the manufacture costs. ${ }^{2,3}$ The industrial energy efficiency has a significant impact on the mitigation of the climate change, security of energy supply and sustainability. Over the past four decades dimensionally stable anodes $\left(\mathrm{DSA}^{\circledR}\right)$ based on $\mathrm{RuO}_{2}$-based mixed oxide catalysts supported onto the titanium substrate played an essential role in the chlor-alkali electrolysis cell. ${ }^{4-6}$ DSA are also involved in many technological applications, such as water electrolysis, electro-organic synthesis and electrochemical oxidation

${ }^{a}$ Physical Chemistry, Saarland University, 66123 Saarbrücken, Germany.E-mail: r.hempelmann@mx.uni-saarland.de

${ }^{b}$ Analytical Chemistry - Electroanalysis and Sensors, Ruhr-University Bochum, 44780 Bochum, Germany

'Inorganic Chemistry, Fritz-Haber-Institute of the Max Planck Society, 14195 Berlin, Germany

${ }^{d}$ Bayer MaterialScience AG, 51368 Leverkusen, Germany

$\dagger$ Electronic supplementary information (ESI) available: SEM images of a commercial $\mathrm{Ru}_{0.3} \mathrm{Ti}_{0.7} \mathrm{O}_{2}$ coating and a crack-free $\mathrm{Ru}_{0.25} \mathrm{Ti}_{0.75} \mathrm{O}_{2}$ coating, $\mathrm{CV}$, XAS spectra of reference compounds: rutile and anatase $\mathrm{TiO}_{2}$, contact angle and XPS. See DOI: $10.1039 / \mathrm{c} 2 \mathrm{cp} 41163 \mathrm{f}$

$\ddagger$ Current address: Institute of Nanotechnology, Karlsruhe Institute of Technology (KIT), 76021 Karlsruhe, Germany. of pollutants. $^{7-9}$ Typically, DSA consist of an electrocatalyst coating with a thickness of a few micrometers to meet the industrial demands of durability for years. ${ }^{10}$ Thermal treatment is necessary for the fabrication of electrode coatings to obtain high crystallinity and mechanical stability for practical applications. ${ }^{11}$ During the thermal treatment, the cracks $(\sim 1 \mu \mathrm{m}$ in crack width, a few $\mu \mathrm{m}$ in crack length) are formed due to the development of tensile stress. Microcracks of the coating surface are commonly found to be prepared by conventional thermal decomposition or by the sol-gel route. ${ }^{12-14}$ Although the crack cavity may accommodate the electrolyte and therefore may offer a more available inner surface area for electrochemical reactions, the penetration of the electrolyte through the cracks results in the deactivation of electrodes due to the attack to the metallic substrate by the electrolyte under the harsh electrolysis conditions. ${ }^{15}$ The analysis of the deactivation mechanism for the DSA shows that the Ti-substrate oxidation results in the loss of performance before the complete dissolution of active ruthenium species, ${ }^{16}$ causing an ineffective use of the precious catalyst materials. This kind of surface structure of anodic coatings is far from satisfactory. Electrode coatings with enhanced catalytic activity and highly available surface area could be fabricated by purposely producing nanoscale catalysts and creating nanoporosity, rather than relying on the microscale cracks. Our previous work has demonstrated that the electrode performance is improved significantly by using nano-catalysts with reduced crystallite size. ${ }^{17}$

The gas bubble effect at the electrode surface is another practical issue on the electrochemical chlorine generation, and 
on other applications as well, such as the $\mathrm{H}_{2}$ and $\mathrm{O}_{2}$ evolution for water electrolysis. ${ }^{18}$ The evolving bubbles could block the electrode surface and impose effects on the mass-transport, which increases the cell voltage in the chlor-alkali industry. ${ }^{3,6}$

Hence, it is of the utmost importance both to improve the anodic coating performance by using nanoscale catalysts, and to explore novel coating microstructures with sufficient durability while concomitantly optimizing the gas bubble evolution behaviour. Although considerable efforts have been made to explore a variety of $\mathrm{RuO}_{2}$-based mixed oxides, ${ }^{19}$ few papers have shed light on the coating surface microstructure, the relative electrode performance and bubble evolution behaviour. ${ }^{20-22}$ The surface microstructure of oxide coatings could impose significant influence both on the catalytic performance and also on the bubble evolution behaviour. Herein, we demonstrate that the compact, crack-free sol-gel $\mathrm{Ru}_{0.3} \mathrm{Sn}_{0.7} \mathrm{O}_{2}$ coatings with a nanoparticle-nanoporosity feature can be used as alternative anodic coatings for the energy-intensive industrial electrolytic chlorine production. A detailed and comparative evaluation was carried out to investigate the effect of the microstructure of the oxide coating on the electrode performance, including stability, catalytic activity and bubble evolution behavior.

\section{Experimental}

\subsection{Preparation of coatings}

Details of the technique have been described elsewhere. ${ }^{23}$ Briefly, the Ti substrates (Goodfellow, diameter $15 \mathrm{~mm}$ ) were sandblasted and then chemically etched in $10 \mathrm{wt} \%$ oxalic acid at $80{ }^{\circ} \mathrm{C}$ for $2 \mathrm{~h}$, and finally rinsed thoroughly with isopropanol. $0.1125 \mathrm{M} \mathrm{Ru}_{0.3} \mathrm{Sn}_{0.7} \mathrm{O}_{2}$ coating solutions were prepared using a sol-gel route. A desired amount of $\mathrm{RuCl}_{3} \cdot x \mathrm{H}_{2} \mathrm{O}(36 \% \mathrm{Ru}, \mathrm{ABCR})$ was dissolved with stirring into isopropanol (solution $\mathrm{A}$ ). $\mathrm{Sn}\left(\mathrm{O}^{i} \mathrm{Pr}\right)_{4} \cdot \mathrm{C}_{3} \mathrm{H}_{7} \mathrm{OH}$ (Alfa Aesar) was added to a mixture of isopropanol and propionic acid (1:1 in volume) and then this solution was refluxed at $150{ }^{\circ} \mathrm{C}$ for $30 \mathrm{~min}$ with vigorous stirring (solution B). After cooling down to room temperature, solution $\mathrm{B}$ was mixed with solution $\mathrm{A}$. The precursor solutions $(50 \mu \mathrm{L})$ were applied onto a Ti-substrate by drop-coating. The wet coatings were air-dried and thermally treated, first at $250{ }^{\circ} \mathrm{C}$ for $10 \mathrm{~min}$, and then at $450{ }^{\circ} \mathrm{C}$ for $5 \mathrm{~min}$ in static air conditions. The procedure was repeated until a final total $\mathrm{Ru}$ loading amount of $5.78 \mathrm{~g} \mathrm{~m}^{-2}$ (metal basis) was achieved. The coatings were finally sintered at $450{ }^{\circ} \mathrm{C}$ for another $1 \mathrm{~h}$ to finish the preparation process. To prepare coatings with reduced microcracks, three diluted sol solutions (diluted in $1: 3,1: 7,1: 31$ ratios in isopropanol) were used and the number of the coating-drying-sintering cycles was increased accordingly. The commercial electrode coatings prepared by a thermal decomposition route were supplied by Bayer MaterialScience, with a nominal composition of $\mathrm{Ru}_{0.3} \mathrm{Ti}_{0.7} \mathrm{O}_{2}$ and a $\mathrm{Ru}$ loading amount of $12.1 \mathrm{~g} \mathrm{~m}^{-2}$ (metal basis).

\subsection{Structural characterisation}

X-ray diffraction patterns (XRD) were collected using a PANalytical X'Pert diffractometer with Ni-filtered $\mathrm{Cu} \mathrm{K} \alpha_{1,2}$ radiation $\left(\lambda_{\mathrm{K} \alpha 1}=1.5406 \AA, \lambda_{\mathrm{K} \alpha 2}=1.5444 \AA\right)$ operated at $45 \mathrm{kV}$ and $40 \mathrm{~mA}$. The crystal structure parameters and crystallite sizes were refined by the Rietveld method using the TOPAS software (Bruker AXS). Crystallite sizes are specified as the volume averaged column heights. The coating surface morphologies were analysed by scanning electron microscopy (SEM) using a JEOL JSM-60 microscope. The surface wettability of the oxide coatings by a water droplet $(20 \mu \mathrm{L})$ was measured in air by a contact angle device (OCA20, DataPhysics Instruments). Near edge X-ray absorption fine structure measurements were performed at the synchrotron radiation facility BESSY II (Helmholtz-Zentrum Berlin, Germany) using the monochromatic radiation of the ISISS beamline. The experiment was conducted in a high-pressure XPS/XAS setup described elsewhere. ${ }^{24}$ The soft X-ray absorption spectra (XAS) of the $\mathrm{Ti} \mathrm{L}_{2,3}$ edges were recorded in the total electron yield mode in the presence of 0.1 mbar He to enhance the signal by secondary electrons created by ionization of the gas phase above the sample. Samples were mounted onto a sapphire sample holder and introduced into the spectrometer. The chemical analysis of the coating surface was based on the X-ray photoelectron spectroscopy (XPS) at different information depths with the applied photoelectron kinetic energies of 200, 450 and $700 \mathrm{eV}$.

\subsection{Scanning electrochemical microscopy (SECM)}

A modified Sensolytics (Bochum, Germany) SECM setup was used. The local activity of the prepared electrodes for $\mathrm{Cl}_{2}$ evolution reactions was visualized by performing SECM using a sample generation-tip collection mode, the details for the measurement strategy and its validity have been described previously. $^{25}$ The sample with a working area of $15 \mathrm{~mm}$ in diameter was used for the measurement. The SECM tip current (the reduction current of $\mathrm{Cl}_{2}$ ) can be deemed as a measure of the catalytic activity of the sample underneath the tip. The tip (Pt microelectrode, $25 \mu \mathrm{m}$ ) was scanned over an area of $300 \times 300 \mu^{2}$ in constant height mode (tip-to-sample distance, $20 \mu \mathrm{m}$ ). The working electrode (sample) was polarized at a potential of $1.4 \mathrm{~V} v s . \mathrm{Ag} / \mathrm{AgCl}(3 \mathrm{M} \mathrm{KCl})$ for the production of $\mathrm{Cl}_{2}$ by oxidation of $\mathrm{Cl}^{-}$. The Pt-tip was polarized at a potential of $0.95 \mathrm{~V}$ vs. $\mathrm{Ag} / \mathrm{AgCl}(3 \mathrm{M} \mathrm{KCl})$ to detect the produced $\mathrm{Cl}_{2}$. The supporting electrolyte was $5 \mathrm{M} \mathrm{NaCl}(\mathrm{pH}$ 2). All SECM measurements were carried out at room temperature.

\subsection{Electrochemical characterization}

Cyclic voltammetry (CV) and galvanostatic polarization measurements were performed in $3.5 \mathrm{M} \mathrm{NaCl}(\mathrm{pH} \mathrm{3)}$ with forced electrolyte flow $\left(100 \mathrm{~mL} \mathrm{~min}^{-1}\right)$ in a home-made teflon cell using a $\mathrm{Pt}$ coated titanium wire as the counter electrode and $\mathrm{Ag} / \mathrm{AgCl}$ $(3.5 \mathrm{M} \mathrm{NaCl})$ as the reference electrode at room temperature and at $80{ }^{\circ} \mathrm{C}$, respectively. The reference electrode was carefully positioned close to the working electrode (with an exposed geometrical area of $1 \mathrm{~cm}^{-2}$ ) by using a Luggin capillary. The measured electrode potential (the average value of the fluctuant potential signal) was corrected for the ohmic resistance of the electrolyte derived by electrochemical impedance spectroscopy.

\subsection{Observation of evolving gas bubbles}

Video imaging of chlorine gas bubble evolution was carried out at room temperature by using a glass beaker as a reaction 
vessel containing $100 \mathrm{~mL} 3.5 \mathrm{M} \mathrm{NaCl}(\mathrm{pH}$ 3) as the electrolyte. The working electrode plate with an exposed surface area of $1.76 \mathrm{~cm}^{2}$ was immersed vertically in the stagnant electrolyte and polarized galvanostatically at $20 \mathrm{~mA} \mathrm{~cm}^{-2}$. A Pt mesh was used as the counter electrode and $\mathrm{Ag} / \mathrm{AgCl}(3.5 \mathrm{M} \mathrm{NaCl})$ as the reference electrode. A CCD camera opposite to the electrode surface was used to image the electrolytically generated $\mathrm{Cl}_{2}$ bubbles. A cold light source was used to illuminate the electrode surface.

\section{Results and discussion}

\subsection{Surface morphology and phase analysis}

To address the effect of the microstructure of the coating on its properties for the electrochemical chlorine evolution, four sol-gel $\mathrm{Ru}_{0.3} \mathrm{Sn}_{0.7} \mathrm{O}_{2}$ coatings with controlled surface microstructure (from mud-crack to crack-free, Fig. 1) were prepared. The deposition of catalyst particles onto the Ti-substrate with desired catalyst loading was obtained by layer-by-layer dropcoating/drying/annealing cycles. The annealing (at $450{ }^{\circ} \mathrm{C}$ ) was used to crystallise the active phase and to reinforce the adhesion of the catalyst at the substrate. Fig. 1a shows the SEM images of a $\mathrm{Ru}_{0.3} \mathrm{Sn}_{0.7} \mathrm{O}_{2}$ ( $\mathrm{RSO}$ ) coating deposited onto a Ti-substrate with a mud-crack island-gap surface microstructure (denoted as $m c$-RSO). In contrast, the state-of-the-art $\mathrm{Ru}_{0.3} \mathrm{Ti}_{0.7} \mathrm{O}_{2}$ coating shows a comparable island size $(\sim 10 \mu \mathrm{m})$ but obviously larger gap width (Fig. S1a, ESI $\dagger$ ). Each island consists of close-packed catalyst particles. The commercial coating shows that most of the islands warp. The formation of the crack structure is generally attributed to the thermally induced tensile stresses. The shrinkage of the xerogel body during the thermal processing is restricted by

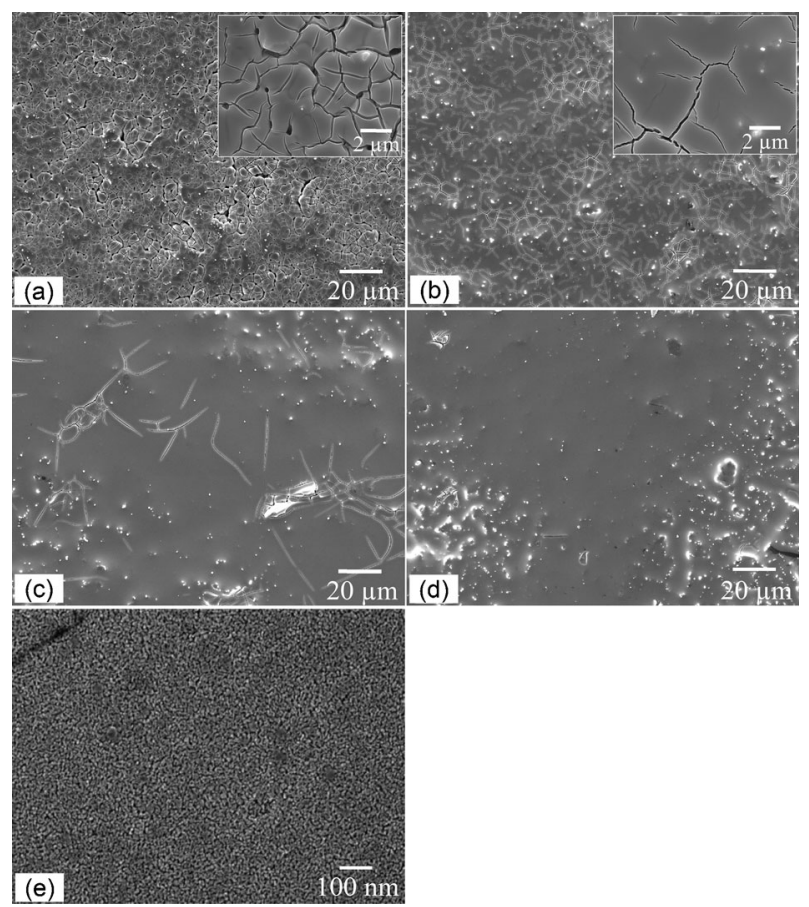

Fig. 1 SEM images of sol-gel $\mathrm{Ru}_{0.3} \mathrm{Sn}_{0.7} \mathrm{O}_{2}$ coatings with different surface microstructure. (a) $m c-\mathrm{RSO}$, (b) $r c$-RSO, (c) $l c-\mathrm{RSO}$, (d) $c f$-RSO, and (e) enlarged image of (d). the underlying substrate. Once the developed stresses exceed the tensile strength of the gel body, cracks develop to release the stress.

The tensile stresses can be minimised by reducing the thickness of each single deposited layer in this preparation strategy, ${ }^{26}$ with a sacrifice of the preparation time. By using gradually diluted sol solutions, coatings with reduced surface cracks (denoted as $r c$-RSO, Fig. 1b), less cracks (denoted as $l c$-RSO, Fig. 1c), and even a crack-free surface (denoted as $c f$-RSO, Fig. 1d) were obtained. The compact oxide coatings (Fig. 1c and d) are composed of close-packed nanocatalyst particles. Furthermore, high resolution SEM shows that the compact parts of the surface consist of a fine and uniform assembly of nanoparticle-nanopore architecture (Fig. 1e). The design of catalysts with open nanoporosity is of particular interest for electrocatalysis. ${ }^{27}$ Coatings with controlled surface microstructures exhibit distinct electrochemical performance, as discussed in the following sections.

The crystal structure and crystallite size of the $\mathrm{Ru}_{0.3} \mathrm{Sn}_{0.7} \mathrm{O}_{2} / \mathrm{Ti}$ electrodes were analysed by using the Rietveld full-pattern refinement method with the Topas software. Except for the diffraction peaks from the Ti-substrate, all $\mathrm{Ru}_{0.3} \mathrm{Sn}_{0.7} \mathrm{O}_{2}$ coatings (Fig. 2a) consist of a single phase $(\mathrm{Sn}-\mathrm{Ru}) \mathrm{O}_{2}$ solid solution structure (space group $\mathrm{P4}_{2} / \mathrm{mmm}$ ), in which the $\mathrm{Ru}^{4+}$ and $\mathrm{Sn}^{4+}$ ions share the same cationic site in the tetragonal rutile sublattice. ${ }^{28}$ The rutile lattice parameters $(a=4.6755, c=3.1742 \AA)$ and the crystallite size $(4.8 \mathrm{~nm})$ were quite similar for all coatings and independent of the preparation processes for the coatings with different surface microstructure. The refined $x$ in $\mathrm{Ru}_{x} \mathrm{Sn}_{1-x} \mathrm{O}_{2}$ is 0.35 based on the refined unit cell parameters using Vegard's rule. ${ }^{17,29}$ The slight off-stoichiometry from the nominal composition was caused presumably by the partial volatilization of the Sn precursor salts before conversion into their oxides. Distinct off-stoichiometry was observed commonly for the

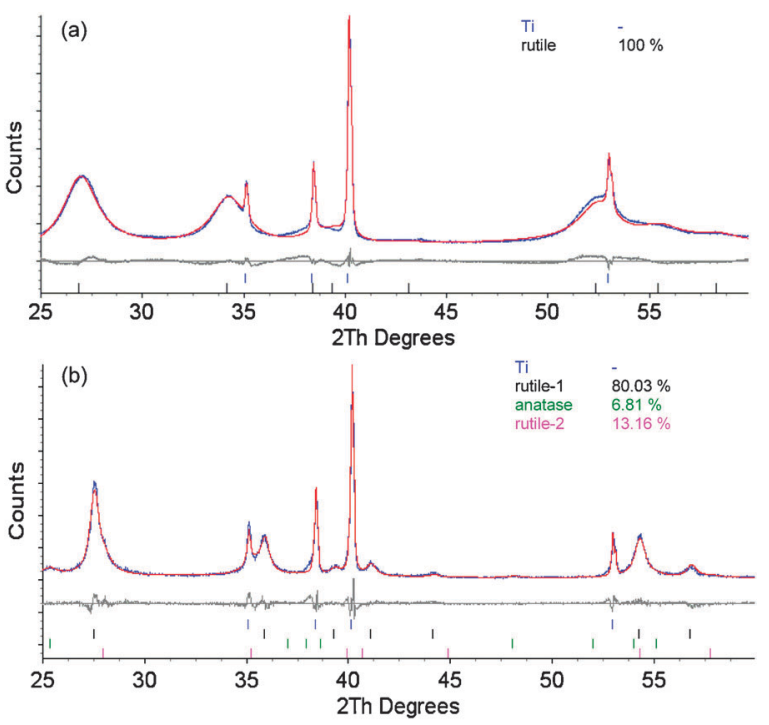

Fig. 2 XRD patterns and Rietveld structure refinement results of (a) $m c$ - RSO and (b) commercial $\mathrm{Ru}_{0.3} \mathrm{Ti}_{0.7} \mathrm{O}_{2}$ coatings. It shows the observed (blue), calculated (red) profiles and the difference plots (grey). The vertical bars below the patterns represent the possible Bragg reflections. The quantitative weight percents were given only for the coating phases. 
$\mathrm{SnO}_{2}$-containing oxide coatings prepared by the conventional thermal decomposition route. ${ }^{30}$

A common difficulty in the preparation of mixed oxide electrode coatings is to obtain both single phase structure and nanoscale catalysts. ${ }^{11,31,32}$ Owing to the controlled hydrolysis and polycondensation reactions, sol-gel synthesis is superior to other techniques to obtain well-controlled stoichiometric target products and intimate mixing of multicomponents at the atomic level. ${ }^{33,34}$ In contrast to the sol-gel $\mathrm{Ru}_{0.3} \mathrm{Sn}_{0.7} \mathrm{O}_{2}$ coatings with single rutile phase and nanocrystalline character, the commercial $\mathrm{Ru}_{0.3} \mathrm{Ti}_{0.7} \mathrm{O}_{2}$ coating prepared by the thermal decomposition route consists of a Ru-poor rutile phase $\left(\mathrm{Ru}_{0.16} \mathrm{Ti}_{0.84} \mathrm{O}_{2}, 80.03 \mathrm{wt} \%\right)$, a Ru-rich rutile phase $\left(\mathrm{Ru}_{0.84} \mathrm{Ti}_{0.16} \mathrm{O}_{2}, 13.16 \mathrm{wt} \%\right)$ and a trace amount of inert anatase $\mathrm{TiO}_{2}$ phase, deduced from the quantitative phase analysis (Fig. 2b). The first two rutile phases are responsible for the catalytic performance, which have a crystallite size of 21 and $10 \mathrm{~nm}$, respectively. The Ru-rich rutile phase (containing about $38 \mathrm{~mol} \%$ of the total ruthenium species in the commercial coating) showed a drawback in the catalyst selectivity for $\mathrm{Cl}_{2}$ evolution reactions. ${ }^{33,35-37}$

Higher fractions of surface atoms can be obtained by using nanocatalysts with reduced crystallite size. ${ }^{17,38}$ The atomic scale surface analysis of $\mathrm{RuO}_{2}$ revealed that the co-ordinatively unsaturated surface atoms of ruthenium and bridging oxygen atoms determine the catalytic reactivity. ${ }^{39}$ To examine the catalytically functional domain of nanoparticles, the extent of surface chlorination of the $\mathrm{Ru}_{0.3} \mathrm{Sn}_{0.7} \mathrm{O}_{2}$ nanocatalysts after the chlorine evolution reactions was determined via an XPS depth profile analysis by changing the photon energy. Trace amounts of chlorine species present in the fresh coating may originate from the chloride precursors. ${ }^{40}$ The ratio of $\mathrm{Cl} /(\mathrm{Ru}+\mathrm{Sn})$ is the highest at the most surface sensitive excitation and decays when deeper layers are also probed (Table S1, ESI $\dagger$ ). This indicates that only a sub-nanometer depth of the catalyst particle surface can be utilized, assuming that the detected chlorine is the chemically adsorbed species $\mathrm{Cl}_{\mathrm{ad}}$ at the catalyst surface. ${ }^{41,42}$ Accordingly, the nanocrystalline character of the prepared $\mathrm{Ru}_{0.3} \mathrm{Sn}_{0.7} \mathrm{O}_{2}$ electrocatalysts $(4.8 \mathrm{~nm})$ exhibits superior performance for the catalytic chlorine evolution reactions in this work, as discussed in Section 3.3.2.

\subsection{Cracks and pores-induced electrolyte penetration}

To evaluate the electrochemical penetration of an electrolyte through the micrometer-scale cracks and nanopores for the mud-crack and crack-free coatings, cyclic voltammetry in a potential range avoiding substantial $\mathrm{Cl}_{2}$ evolution $(0.1-1.0 \mathrm{~V}$ vs. $\mathrm{Ag} / \mathrm{AgCl}$ ) was performed while changing the scan rates from 5 to $200 \mathrm{mV} \mathrm{s}^{-1}$ in $3.5 \mathrm{M} \mathrm{NaCl}, \mathrm{pH} \mathrm{3}$, at room temperature (Fig. S2, ESI $\dagger$ ). The voltammetric charge $\left(q_{\mathrm{a}}\right)$ obtained by integrating the anodic branch of the cyclic voltammogram has been used as a measure of the accessible electroactive surface area. ${ }^{43,44}$ The reactant species may diffuse into the micrometer-wide gaps and nanopores during the potential sweep, making full use of the catalyst surface. The diffusion-controlled penetration behavior of the electrolyte during the $\mathrm{CV}$ measurements can be evaluated from the dependence of the voltammetric charge on the scan rate. More surface area from the inner cracks and pores can be utilized at

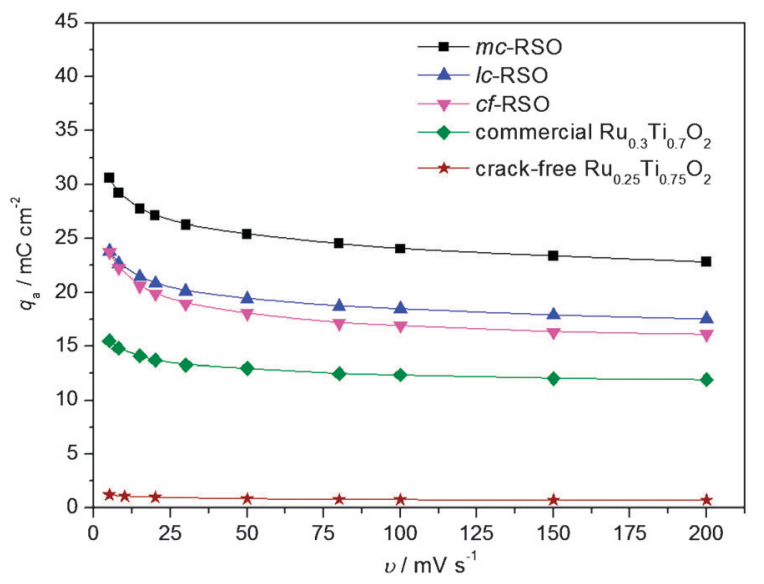

Fig. 3 Dependence of voltammetric charge $\left(q_{\mathrm{a}}\right)$ on the potential sweep rate (v). CV measurements were carried out in $3.5 \mathrm{M} \mathrm{NaCl}$, $\mathrm{pH} 3$, at room temperature in a voltage range of $0.1-1.0 \mathrm{~V} v \mathrm{~s} . \mathrm{Ag} / \mathrm{AgCl}$ $(3.5 \mathrm{M} \mathrm{NaCl})$ at variable scan rates. A commercial $\mathrm{Ru}_{0.3} \mathrm{Ti}_{0.7} \mathrm{O}_{2}$ coating and a crack-free $\mathrm{Ru}_{0.25} \mathrm{Ti}_{0.75} \mathrm{O}_{2}$ coating ${ }^{20}$ were used for comparison.

lower scan rates, indicating a high value of $q_{\mathrm{a}}$, as shown in Fig. 3. This is a common observation for the mud-crack coatings. ${ }^{45}$ The results in Fig. 3 also imply a highly accessible open nanoporosity for the compact $l c$-RSO and $c f$-RSO coatings and a higher electroactive surface area of the $\mathrm{Ru}_{0.3} \mathrm{Sn}_{0.7} \mathrm{O}_{2}$ nanocatalysts as compared with the commercial $\mathrm{Ru}_{0.3} \mathrm{Ti}_{0.7} \mathrm{O}_{2}$.

In comparison with the compact coatings ( $l c-, c f$-RSO), the $m c$-RSO coating shows an increase of $q_{\mathrm{a}}$ by about $30 \%$ due to the contribution of the cross-sectional surface area from the microcracks. Nevertheless, the coating surface with a compact structure is desired to eliminate the straightforward penetration path of the electrolyte and its attack of the underlying Ti-substrate. This could effectively prolong the lifetime under the harsh industrial electrolysis conditions. In addition, this compact coating could resist the mechanical erosion of coating exfoliation caused by the turbulent hydrodynamic conditions of bubble evolution and electrolyte convection. ${ }^{10}$

In order to examine whether the electrolyte can reach and attack the underlying Ti-substrate through the gaps of the mud-crack coating, which may result in the formation of an insulating $\mathrm{TiO}_{x}$ interlayer, the Ti L-edge XAS spectra were recorded in total electron yield (TEY) mode for a fresh and a used mud-crack $\mathrm{Ru}_{0.3} \mathrm{Sn}_{0.7} \mathrm{O}_{2}$ coating deposited onto a Ti-substrate (Fig. 4). The TEY absorption spectrum in the soft X-ray energy range is nearly as surface sensitive as the corresponding XPS investigation, however allowing to probe the surface state in the valley of the cracks. Two sets of peaks ( $L_{3}$ and $L_{2}$ edges) corresponding to the $2 p_{3 / 2}$ and $2 p_{1 / 2}$ excitation of the $2 p^{6} 3 d^{0}$ to $2 p^{5} 3 d^{1}$ transition were observed for the sample after the electrochemical measurements (Fig. 4a), revealing the presence of a $\mathrm{TiO}_{x}$ structure at the $\mathrm{Ru}_{0.3} \mathrm{Sn}_{0.7} \mathrm{O}_{2}$-Ti interface. ${ }^{46,47}$ It is very unlikely that the $\mathrm{TiO}_{x}$ is derived from the sintering preparation processes, since the characteristic Ti L-edges were not observed in the fresh sample (Fig. 4b). The formation of a $\mathrm{TiO}_{x}$ interlayer for the $\mathrm{RuO}_{2}-\mathrm{TiO}_{2} / \mathrm{Ti}$ electrode was mainly deduced from the impedance data due to the presence of a new semicircle in the high frequency region of the Nyquist plot from 


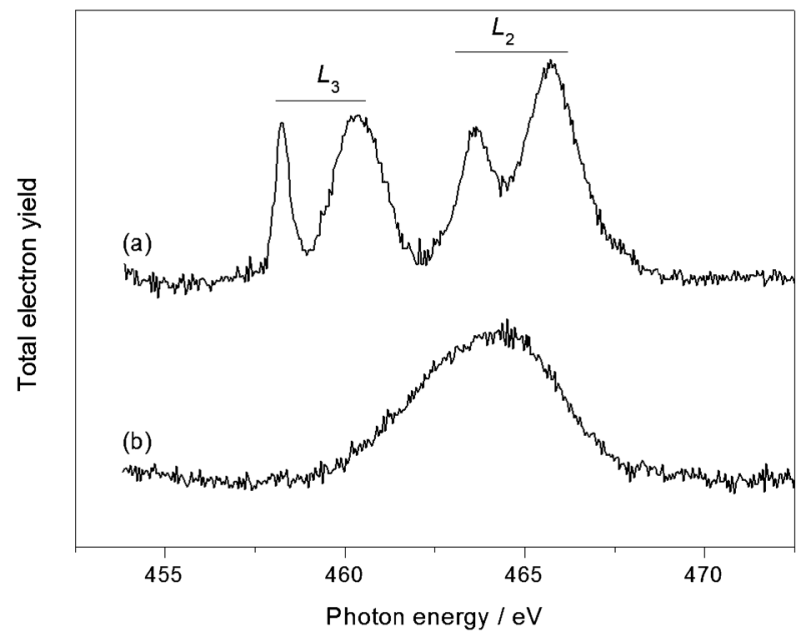

Fig. $4 \mathrm{Ti} \mathrm{L}_{2,3}$-edge X-ray absorption spectra of the mud-crack $\mathrm{Ru}_{0.3} \mathrm{Sn}_{0.7} \mathrm{O}_{2}$ coatings supported onto Ti substrates: (a) used sample and (b) fresh sample.

previous studies. ${ }^{48,49}$ The formation of a $\mathrm{TiO}_{x}$ interlayer increases the film resistance and results in the electrode deactivation. The present work is a direct experimental evidence showing that the $\mathrm{TiO}_{x}$ interlayer between the $\mathrm{Ru}_{0.3} \mathrm{Sn}_{0.7} \mathrm{O}_{2}$ layer and the Ti-substrate is formed due to the penetration of the electrolyte through the microcracks and its attack of the metallic substrate.

The compact coatings $l c$-RSO and $c f$-RSO behave differently than the previously investigated crack-free $\mathrm{Ru}_{0.25} \mathrm{Ti}_{0.75} \mathrm{O}_{2}$ coating. ${ }^{20}$ The latter is truly dense and without observable nanopores existing at the coating surface (Fig. S1b, ESI $\dagger$ ). In comparison to the nanoporous $\mathrm{Ru}_{0.3} \mathrm{Sn}_{0.7} \mathrm{O}_{2}$ coating, the structural densification of the $\mathrm{Ru}_{0.25} \mathrm{Ti}_{0.75} \mathrm{O}_{2}$ coating may be related to the particle growth, agglomeration and the difference in the synthesis chemistry. The $\mathrm{Ru}_{0.25} \mathrm{Ti}_{0.75} \mathrm{O}_{2}$ coating is impermeable for the electrolyte demonstrated by the fact that $q_{\mathrm{a}}$ is independent of the scan rate (Fig. 3), indicating only outer-most surface response to the potential scan.

Despite the fact that compact coatings are promising to assure the long-term durability for industrial applications, its effect on the catalytic performance and the $\mathrm{Cl}_{2}$ bubble evolution behaviour is yet unclear. The following investigation of the catalytic activity as well as the bubble evolution behavior of mud-crack and compact coatings were performed in order to obtain a fundamental understanding of correlations of the coating microstructure and the electrocatalytic properties.

\subsection{Chlorine evolution activity}

3.3.1 SECM visualization of the local electrocatalytic activity. Considering that the SECM-tip diameter $(25 \mu \mathrm{m})$ is much larger than the width and length of an individual surface crack (see Fig. 1), the local activity analysis for an individual crack cannot be achieved in this case. The detected tip current (the reduction current of the dissolved $\mathrm{Cl}_{2}$ at the SECM tip) represents a local average activity for the region underneath the tip. The sample generation-tip collection mode of SECM for monitoring the local concentration of the dissolved $\mathrm{Cl}_{2}$ in the vicinity of the working electrode is only suitable for low
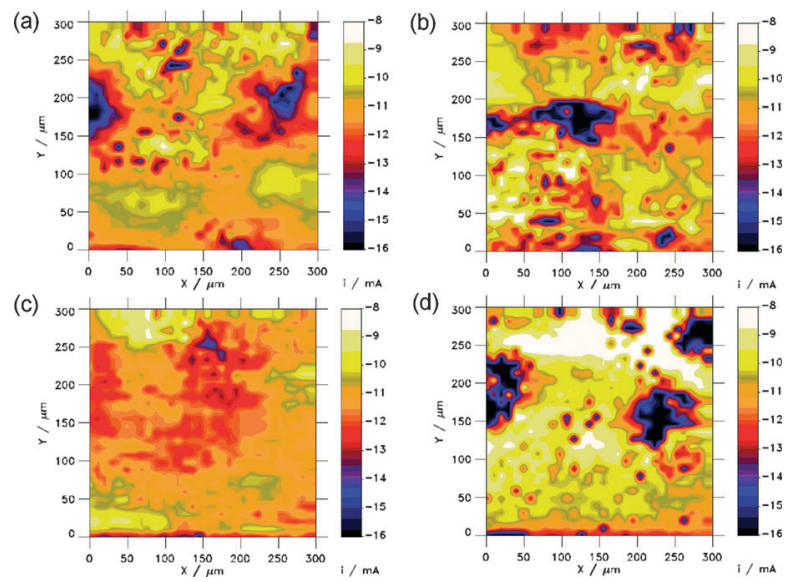

Fig. 5 (a-d) SECM activity images of $\mathrm{Ru}_{0.3} \mathrm{Sn}_{0.7} \mathrm{O}_{2}$ coatings with controlled surface microstructure corresponding to Fig. 1a-d. The activity increases from pale-yellow to blue-black (see color bars). SECM imaging was performed with a $25 \mu \mathrm{m}$ Pt tip in $5 \mathrm{M} \mathrm{NaCl}$, $\mathrm{pH} 2$, at room temperature. The polarization potentials for the sample and Pt-tip were 1.4 and $0.95 \mathrm{~V}$ vs. $\mathrm{Ag} / \mathrm{AgCl}(3 \mathrm{M} \mathrm{KCl})$, respectively.

polarization potentials, ${ }^{25}$ in which the surface coverage problem caused by the bubble formation can be neglected. The location of the more active spots (blue-black region in Fig. 5) over the scanned areas can be easily visualized in the SECM images. For $m c$-, $l c$ - and $c f$-RSO coatings, the more active spots show an about two-fold larger tip-current than the one for the less active regions. In contrast, a three-fold difference was observed for the commercial $\mathrm{Ru}_{0.3} \mathrm{Ti}_{0.7} \mathrm{O}_{2}$ coating (data not shown) indicating a relative heterogeneous microstructure. ${ }^{50}$ The local activity visualization of chlorine evolution at the commercial $\mathrm{Ru}_{0.3} \mathrm{Ti}_{0.7} \mathrm{O}_{2}$ anodes by means of SECM has been reported elsewhere. ${ }^{25}$ The distribution of active spots in the case of the $l c$-RSO coating (Fig. 5c) is more uniform than the one for other coatings. Since the surface roughness $(<1 \mu \mathrm{m})$ of the prepared electrode coatings is far below the value of the tip-to-sample distance $(20 \mu \mathrm{m})$ the observed variations in the local activity reflect indeed the features of the coatings. The averaged tip-current over the scanned region is about $-11.2 \mathrm{~mA}$ for all the $\mathrm{Ru}_{0.3} \mathrm{Sn}_{0.7} \mathrm{O}_{2}$ coatings, which is roughly twice as large as the one for the commercial $\mathrm{Ru}_{0.3} \mathrm{Ti}_{0.7} \mathrm{O}_{2}$ coating, indicating a significantly improved catalytic activity. Since only ruthenium is the catalytically active component for chlorine evolution in both cases, the enhanced activity of the sol-gel derived $\mathrm{Ru}_{0.3} \mathrm{Sn}_{0.7} \mathrm{O}_{2}$ coating seems to be due to the nanoporous microstructure. The similarity in the averaged local activity of the $\mathrm{Ru}_{0.3} \mathrm{Sn}_{0.7} \mathrm{O}_{2}$ coatings allows an independent evaluation of the surface microstructure effect on the overall activity and the bubble evolution behavior. The distribution of active sites at the micrometer-scale level could impose effects on the local generation rate of $\mathrm{Cl}_{2}$ bubbles and accordingly the distribution in the bubble size (as discussed in Section 3.4.1). It is reasonable to assume that the local activity of the electrode coatings along with its bubble evolution behavior is determining the apparent overall performance.

3.3.2 Overall activity. The overall catalytic activities for chlorine evolution of the $\mathrm{Ru}_{0.3} \mathrm{Sn}_{0.7} \mathrm{O}_{2}$ coatings and a commercial coating are compared in Fig. 6. The galvanostatic polarization 


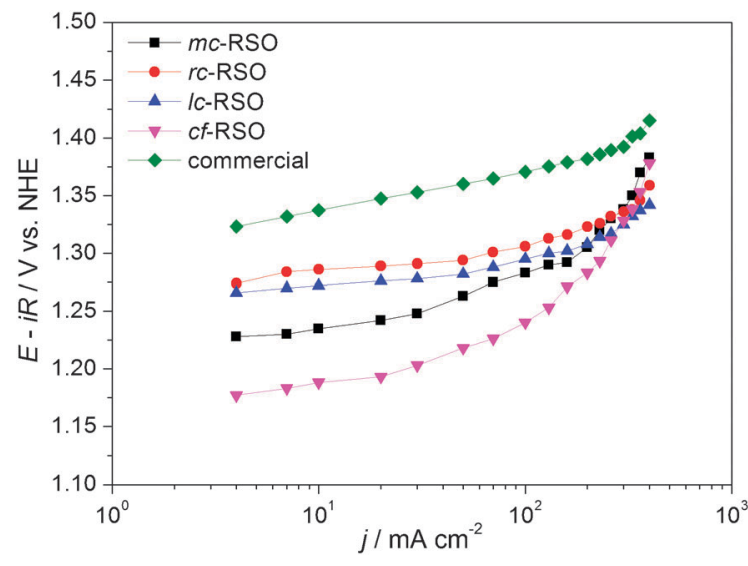

Fig. 6 Polarization curves measured galvanostatically in $3.5 \mathrm{M} \mathrm{NaCl}$, $\mathrm{pH} \mathrm{3}$, at $80{ }^{\circ} \mathrm{C}$ with forced convection of the electrolyte for $\mathrm{Ru}_{0.3^{-}}$ $\mathrm{Sn}_{0.7} \mathrm{O}_{2}$ coatings (5.78 $\mathrm{g} \mathrm{Ru} \mathrm{m}^{-2}$ ) with controlled surface microcrack structure and a commercial $\mathrm{Ru}_{0.3} \mathrm{Ti}_{0.7} \mathrm{O}_{2}$ coating $\left(12.1 \mathrm{~g} \mathrm{Ru} \mathrm{m}^{-2}\right)$.

behaviour indicates that all $\mathrm{Ru}_{0.3} \mathrm{Sn}_{0.7} \mathrm{O}_{2}$ coatings show better performance than the commercial $\mathrm{Ru}_{0.3} \mathrm{Ti}_{0.7} \mathrm{O}_{2}$ coating measured under identical conditions. A decrease of the cell voltage by tens of millivolts means a considerable reduction of energy consumption for the chlor-alkali industry., ${ }^{3,6}$ The higher activity of the $\mathrm{Ru}_{0.3} \mathrm{Sn}_{0.7} \mathrm{O}_{2}$ coatings is probably due to the facilitated diffusion and the transport of the reactive species and products through the nanocatalyst-nanopore framework. Interestingly, the compact coatings ( $l c-, c f$-RSO) show comparable activity to the mud-crack coatings ( $m c-, r c$-RSO) tested under quasi-practical conditions $\left(400 \mathrm{~mA} \mathrm{~cm}^{-2}, 80{ }^{\circ} \mathrm{C}\right)$. This reveals that the crack-free coatings can be used as an alternative for the stateof-the-art mud-crack coatings without loss of catalytic activity. Besides, the compact coatings could provide an improved longterm durability due to its protective character for the Ti-substrate.

Although the polarization behavior at high applied current densities $\left(>260 \mathrm{~mA} \mathrm{~cm}{ }^{-2}\right)$ is similar for all $\mathrm{Ru}_{0.3} \mathrm{Sn}_{0.7} \mathrm{O}_{2}$ coatings, the electrode potential in the lower applied current density region (4-100 $\mathrm{mA} \mathrm{cm} \mathrm{cm}^{-2}$ ) is rather different (Fig. 6). Considering the similar intrinsic activity for all samples as confirmed by SECM, the difference in electrode potential is supposed to be exclusively caused by the difference in the bubble coverage of the electrode coatings. The polarization curves are depicted in terms of the electrode potential versus the apparent current density (the current divided by the geometric electrode surface). The sample $c f$-RSO exhibits an earlier change in the shape of the polarization curve. Obviously, this sample suffers earlier from mass transport limitations or changes in the Tafel slope. The Tafel slopes differ in the high current density region. The sample $l c$-RSO becomes the best at the technically relevant current density. Simultaneously, this is the sample that shows a very uniform distribution in the size of the bubbles (see Fig. 7b) and also the most uniform distribution of catalytic activity in the SECM images (see Fig. 5c). It is assumed that the effective electrode surface area varies with the bubble coverage. If the coating surface is severely shielded by $\mathrm{Cl}_{2}$ bubbles, the effective surface area is decreased dramatically which is equivalent to a polarization of the electrode at a higher current density. Taking the potential values measured at $20 \mathrm{~mA} \mathrm{~cm}{ }^{-2}$ as an example, optical observation of evolving bubbles at the electrode surface was carried out (Section 3.4) to elucidate the reasons for the observed difference in potential values in Fig. 6 in the region of lower applied current densities.

\subsection{Bubble evolution behavior}

$\mathrm{Cl}_{2}$ bubbles appear at the electrode surface after a supersaturation of dissolved $\mathrm{Cl}_{2}$ in the vicinity of the electrode-electrolyte interface has been achieved. The coverage of the surface with gas bubbles decreases the available surface area which concomitantly has to provoke an increased current density at the remaining surface. This will increase the overpotential and consequently the rate constant of the reaction on the remaining surface. Besides the catalyst materials the micrometer-scale surface structure is one of the critical factors influencing the $\mathrm{Cl}_{2}$ bubble evolution behavior.

Fig. 7 shows the evolution of chlorine bubbles at an applied moderate current density of $20 \mathrm{~mA} \mathrm{~cm}{ }^{-2}$ using an optical video microscopy. Intensive bubble evolution at higher current densities $\left(>50 \mathrm{~mA} \mathrm{~cm}^{-2}\right)$ is characterized by numerous tiny bubbles with fast release from the electrode surface, which makes bubble analysis by direct optical observation difficult. The observation of bubbles was performed using a glass beaker as container for the electrolyte. The working electrode was aligned vertically and polarized to the predefined current density using a galvanostat. Once the step current is applied, the potential for the working electrode jumps sharply and then reaches slowly a plateau corresponding to the steady-state potential of the electroactive species. Accordingly, the $\mathrm{Cl}_{2}$ bubbles emerge at the electrode surface and then grow and shield the electrode surface. Finally, the bubble size and the coverage fraction of the electrode surface approach a steady state in line with the steady-state polarization conditions. The capillary force anchors the bubbles to the nucleation sites, balancing the buoyancy force for bubble detachment. ${ }^{51}$ Bubble detachment can be observed with further continuous polarization of the electrode. Representative video frames as shown in Fig. 7 are snap-shots recorded at steady-state conditions.

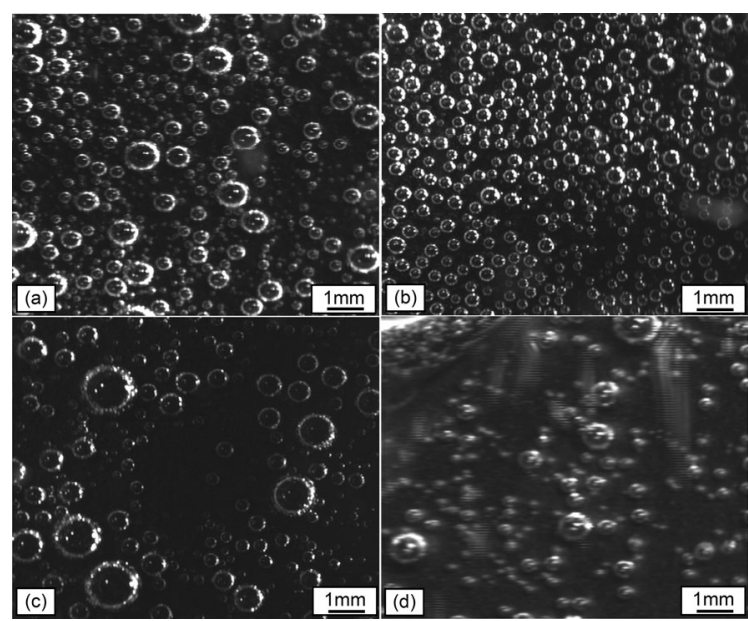

Fig. 7 Representative frames taken from video imaging of steady state bubble evolution in $3.5 \mathrm{M} \mathrm{NaCl}, \mathrm{pH} 3$, at room temperature, $j=20 \mathrm{~mA} \mathrm{~cm}{ }^{-2}$ for (a) $m c$-RSO, (b) $l c$-RSO, (c) $c f$-RSO and (d) a commercial $\mathrm{Ru}_{0.3} \mathrm{Ti}_{0.7} \mathrm{O}_{2}$ coating. 
A distinct bubble evolution behavior was observed for the $m c-, l c-, c f$-RSO coatings in comparison with the commercial coating. The surface-anchored bubbles shield severely the $\mathrm{Ru}_{0.3} \mathrm{Sn}_{0.7} \mathrm{O}_{2}$ surface. The apparent water contact angles measured for all $\mathrm{Ru}_{0.3} \mathrm{Sn}_{0.7} \mathrm{O}_{2}$ coatings indicate a much more hydrophilic surface compared to the commercial coating (Fig. S4, ESI $\dagger$ ). Interestingly, the $c f$-RSO coating shows a super-hydrophilic character. Accordingly, we observed that the bubbles detach easily from the $c f$-RSO coating leading to a relative low surface coverage compared to the $m c$ - or $l c$-RSO coatings. A similar observation was reported for surface wetting effects on $\mathrm{H}_{2}$ evolution. ${ }^{22}$ The large chemical heterogeneity of the coating could result in a broad distribution in the bubble size. Accordingly, we observed that smaller and bigger bubbles coexist at the commercial electrode surface. In contrast, the distribution in the bubble size is comparatively smaller for the $\mathrm{Ru}_{0.3} \mathrm{Sn}_{0.7} \mathrm{O}_{2}$ coatings, in particular for the $l c$-RSO coating (Fig. 7b). This is consistent with the uniform distribution of the active spots observed from SECM in Fig. 5c.

The bubble coverage for the $m c$-, $l c-, c f$-RSO coatings in Fig. 7 (coverage fraction: $l c>m c>c f$ ) could elucidate the observed difference in the polarization potential in Fig. 6 (electrode potential at $20 \mathrm{~mA} \mathrm{~cm}{ }^{-2}: l c>m c>c f$ ), since only the exposed electrode surface is available for the adsorption of the approaching $\mathrm{Cl}^{-}$ions. Under these conditions, the polarization behaviour is governed by ohmic effects induced by bubble evolution. At high applied current densities, tiny bubbles evolve at the electrode surface and the influence of bubble coverage on the electrode potential fades away. Hence, in this case the electrode reactions are dominated by the intrinsic catalytic activity of the coating materials along with the mass transfer.

We observed that the bubbles form, grow and then detach at specific sites of the coating. The bubble nucleation obeys a heterogeneous nucleation mechanism at the electrode surface. These specific sites could be identical with the more active spots observed from SECM analysis. Bubble nucleation and growth occur preferably on these spots. The bubbles accumulate at the surface to a much larger size by sacrificing the neighboring small bubbles and by accommodating the newly generated $\mathrm{Cl}_{2}$ gas, which diffuses through the electrolyte-bubble meniscus interface driven by the concentration gradient of the dissolved $\mathrm{Cl}_{2}$ between the surrounding electrolyte and the bubble surface.

The optical observation of the gas bubble formation, growth and release enables us to obtain intuitional information concerning the average bubble size, the size distribution, the population number, etc. under moderate polarization conditions. However, quantitative analysis of the renewal of the exposure of the electrode surface and of the detachment frequency of evolving bubbles are difficult. The statistical character of bubble events occurring at the coating has to be analyzed by performing wavelet transformation of the bubble-induced potential noise signals. This will be discussed in detail in future work.

\section{Conclusions}

In summary, sol-gel $\mathrm{Ru}_{0.3} \mathrm{Sn}_{0.7} \mathrm{O}_{2}$ coatings with a novel compact and crack-free microstructure have been synthesized and investigated in comparison with mud-crack $\mathrm{Ru}_{0.3} \mathrm{Sn}_{0.7} \mathrm{O}_{2}$ coatings and a state-of-the-art commercial mud-crack $\mathrm{Ru}_{0.3} \mathrm{Ti}_{0.7} \mathrm{O}_{2}$ coating. We have demonstrated that the compact $\mathrm{Ru}_{0.3} \mathrm{Sn}_{0.7} \mathrm{O}_{2}$ coating can be used as a candidate for electrochemical chlorine evolution reactions, which shows better activity than the commercial $\mathrm{Ru}_{0.3} \mathrm{Ti}_{0.7} \mathrm{O}_{2}$ coating and catalytic properties comparable to the mud-crack $\mathrm{Ru}_{0.3} \mathrm{Sn}_{0.7} \mathrm{O}_{2}$ coating tested under quasi-practical conditions. The dependence of the $\mathrm{Cl}_{2}$ bubble evolution behaviour on the coating of the microstructure and polarization conditions was evaluated and uniform bubble formation is supposed to be in line with the SECM results visualizing the local electrocatalytic activity of the sample. The combination of the nanocatalysts with an optimized coating microstructure is promising for boosting the energy and resource efficiency in the chlor-alkali industry and consequently reduces the energy-related $\mathrm{CO}_{2}$ emissions.

\section{Acknowledgements}

Financial support from the joint BMBF project in the framework of "Innovative Technologies for Resource Efficiency-ResourceIntensive Production Processes: Improving the efficiency of chlorine production" (FKZ: 033R018A, 033R018D, 033R018E and 033R018G) is gratefully acknowledged. We thank S. Kuhn for the SEM measurements.

\section{References}

1 J. Pérez-Ramírez, C. Mondelli, T. Schmidt, O. F. K. Schlüter, A. Wolf, L. Mleczko and T. Dreier, Energy Environ. Sci., 2011, 4, 4786.

2 J. Fauvarque, Pure Appl. Chem., 1996, 68, 1713.

3 I. Moussallem, J. Jörissen, U. Kunz, S. Pinnow and T. Turek, J. Appl. Electrochem., 2008, 38, 1177.

4 H. B. Beer, British Pat., 1147 442, 1965.

5 O. De Nora, Chem. Eng. Technol., 1970, 42, 222.

6 S. Trasatti, Electrochim. Acta, 2000, 45, 2377.

7 S. D. Li, C. C. Wang and C. Y. Chen, Electrochim. Acta, 2009, 54, 3877.

8 K. W. Kim, Y. J. Kim, I. T. Kim, G. I. Park and E. H. Lee, Electrochim. Acta, 2005, 50, 4356.

9 L. C. Chiang, J. E. Chang and T. C. Wen, Water Res., 1995, 29, 671.

10 Y. Takasu, W. Sugimoto, Y. Nishiki and S. Nakamatsu, J. Appl. Electrochem., 2010, 40, 1789.

11 Yu. E. Roginskaya, I. D. Belova, B. Sh. Galyamov, F. Kh. Chibirova and R. R. Shifrina, Mater. Chem. Phys., 1989, 22, 203.

12 S. Trasatti, Electrochim. Acta, 1991, 36, 225.

13 V. V. Panić, A. Dekanski, S. K. Milonjić, R. T. Atanasoski and B. Ž. Nikolić, Colloids Surf., A, 1999, 157, 269.

14 G. R. P. Malpass, R. S. Neves and A. J. Motheo, Electrochim. Acta, 2006, 52, 936.

15 P. Kohl and K. Lohrberg, J. Appl. Electrochem., 1989, 19, 589.

16 A. S. Pilla, E. O. Cobo, M. M. E. Duarte and D. R. Salinas, J. Appl. Electrochem., 1997, 27, 1283.

17 R. Chen, V. Trieu, H. Natter, K. Stöwe, W. F. Maier, R. Hempelmann, A. Bulan, J. Kintrup and R. Weber, Chem. Mater., 2010, 22, 6215.

18 H. Matsushima, T. Nishida, Y. Konishi, Y. Fukunaka, Y. Ito and K. Kuribayashi, Electrochim. Acta, 2003, 48, 4119.

19 S. Trasatti, Electrochim. Acta, 1984, 29, 1503.

20 F. Huet, M. Musiani and R. P. Nogueira, J. Solid State Electrochem., 2004, 8, 786

21 K. I. Popov, N. D. Nikolić, P. M. Živković and G. Branković, Electrochim. Acta, 2010, 55, 1919.

$22 \mathrm{H}$. Bouazaze, S. Cattarin, F. Huet, M. Musiani and R. P. Nogueira, J. Electroanal. Chem., 2006, 597, 60.

23 R. Chen, V. Trieu, H. Natter, R. Hempelmann, A. Bulan, J. Kintrup and R. Weber, DE, 102010043085.4, 2010. 
24 A. Knop-Gericke, E. V. Kleimenov, M. Hävecker, R. Blume, D. Teschner, S. Zafeiratos, R. Schlögl, V. I. Bukhtiyarov, V. V. Kaichev, I. P. Prosvirin, A. I. Nizovskii, H. Bluhm, A. Barinov, P. Dudin and M. Kiskinova, Adv. Catal., 2009, 52, 213.

25 A. R. Zeradjanin, T. Schilling, S. Seisel, M. Bron and W. Schuhmann, Anal. Chem., 2011, 83, 7645.

26 G. G. Stoney, Proc. R. Soc. London, Ser. A, 1909, 82, 172.

27 R. Wang, C. Xu, X. Bi and Y. Ding, Energy Environ. Sci., 2012, 5, 5281.

28 J. Gaudet, A. C. Tavares, S. Trasatti and D. Guay, Chem. Mater., 2005, 17, 1570.

29 L. Vegard, Z. Phys., 1921, 5, 17.

30 H. Asano, T. Shimamune and Y. Matsumoto, US Pat., 4668531 , 1987.

31 J. C. Forti, P. Olivi and A. R. de Andrade, Electrochim. Acta, 2001, 47, 913.

32 X. Wang, D. Tang and J. Zhou, Trans. Nonferrous Met. Soc. China, 2004, 14, 1111.

33 X. Wang, D. Tang and J. Zhou, J. Alloys Compd., 2007, 430, 60.

34 O. Lev, Z. Wu, S. Bharathi, V. Glezer, A. Modestov, J. Gun, L. Rabinovich and S. Sampath, Chem. Mater., 1997, 9, 2354.

35 H. A. Hansen, I. C. Man, F. Studt, F. Abild-Pedersen, T. Bligaard and J. Rossmeisl, Phys. Chem. Chem. Phys., 2010, 12, 283.

36 P. C. S. Hayfield, Platinum Met. Rev., 1998, 42, 46.

37 T. Arikawa, Y. Murakami and Y. Takasu, J. Appl. Electrochem., $1998,28,511$.

38 R. Schlögl and S. B. Abd Hamid, Angew. Chem., Int. Ed., 2004, 43, 1628.
39 H. Over, Y. D. Kim, A. P. Seitsonen, S. Wendt, E. Lundgren, M. Schmid, P. Varga, A. Morgante and G. Ertl, Science, 2000, 287, 1474 .

40 L. Vázquez-Gómez, E. Horváth, J. Kristóf and A. De Battisti, Thin Solid Films, 2006, 515, 1819.

41 N. López, J. Gómez-Segura, R. P. Marín and J. Pérez-Ramírez, J. Catal., 2008, 255, 29.

42 A. De Battisti, S. Ferro and M. D. Colle, J. Phys. Chem. B, 2001, 105, 1679 .

43 D. Galizzioli, F. Tantardini and S. Trasatti, J. Appl. Electrochem., 1974, 4, 57.

44 L. M. Doubova, S. Daolio and A. De Battisti, J. Electroanal. Chem., 2002, 532, 25.

45 A. Bandi, I. Vartires, A. Mihelis and C. Hainrosie, J. Electroanal. Chem., 1983, 157, 241.

46 G. S. Henderson, X. Liu and M. E. Fleet, Phys. Chem. Miner., 2002, 29, 32.

47 J. P. Crocombette and F. Jollet, J. Phys.: Condens. Matter, 1994, 6, 10811 .

48 V. A. Alves, L. A. da Silva and J. F. C. Boodts, J. Appl. Electrochem., 1998, 28, 899.

49 S. M. Hoseinieh, F. Ashrafizadeh and M. H. Naddahi, J. Electrochem. Soc., 2010, 157, E50.

50 Yu. E. Roginskaya and C. V. Morozova, Electrochim. Acta, 1995, 40, 817.

51 G. Liger-Belair, M. Vignes-Adler, C. Voisin, B. Robillard and P. Jeandet, Langmuir, 2002, 18, 1294. 